\title{
IbM PORTABLE INSULATED FISH STORAGE BOX UNTUK NELAYAN DESA SUMBERBENING KABUPATEN MALANG
}

\author{
Syarifah Hikmah Julinda Sari ${ }^{1}$, Hartati Kartikaningsih ${ }^{2}$, Defri Yona ${ }^{3}$ \\ Fakultas Perikanan dan Ilmu Kelautan, Universitas Brawijaya \\ Jalan Veteran Malang 65145 \\ ${ }^{1}$ syarifahsari@ub.ac.id \\ 2hartatikartikan@ub.ac.id \\ 3defri.yona@ub.ac.id
}

\begin{abstract}
ABSTRAK
Desa Sumberbening terletak di Pesisir Pantai Kondangmerak dan berpenduduk mayoritas adalah nelayan yang menggunakan perahu yang berukuran sedang untuk menangkap ikan dan menyimpan hasil tangkapannya sebelum di labuhkan ke pelabuhan terdekat untuk dipasarkan. Permasalahan yang dialami oleh Mitra IbM yaitu pada kondisi tempat penyimpanan sehingga es mudah mencair dan menurunkan kualitas ikan tangkapan. Solusi yang ditawarkan untuk mengatasi masalah diatas adalah dengan memberikan bantuan alat portable insulated fish storage box pada mitra IbM yaitu sebuah kotak berinsulasi, yang akan mempertahankan kondisi dingin lebih lama karena es tidak mudah mencair. Selain itu, alat tersebut bisa dipindah-pindah sehingga memudahkan penanganan ikan untuk dipasarkan dan dipindahkan apabila kapal/perahu tidak beroperasi sehingga keamanan alat tersebut bisa terjaga. Kurangnya keterampilan fish handling dan sanitasi pada mitra akan diatasi dengan pelatihan penanganan ikan sehingga mutu ikan yang dijual akan baik dan pada akhirnya akan membantu menaikkan kesejahteraan nelayan Desa Sumberbening.
\end{abstract}

Keywords- Portable insulated fish storage box, fish handling, Kondang Merak, Malang

\section{PENDAHULUAN}

Usaha perikanan tangkap merupakan salah satu sektor utama pendapatan Negara Indonesia. Peluang dan prospek perikanan Indonesia masih sangat besar dan menjanjikan. Hal ini terbukti dengan perkiraan jumlah sumberdaya perikanan yang lestari sebesar 90 juta ton, baru sekitar 5.9 juta ton yang termanfaatkan. Oleh karena itu, usaha perikanan tangkap dapat terus dikembangkan. Pengembangan usaha perikanan tangkap tidak hanya terbatas pada pengembangan kapal untuk menangkap ikan, tapi juga usaha untuk menjaga kesegaran ikan setelah ditangkap.

Kesegaran ikan hasil tangkapan sangat penting untuk menjaga kualitas ikan sehingga nilai jualnya tidak turun. Ikan yang diperlakukan dengan tidak tepat setelah ditangkap dapat menurunkan kualitasnya yang pada akhirnya akan menurunkan nilai jualnya. Penanganan ikan yang tepat dilakukan dengan menurunkan dan menjaga suhu tubuh ikan setelah ditangkap agar kesegarannya tetap maksimal. Hal ini dapat dilakukan dengan menggunakan media pendingin yang berfungsi untuk menarik atau memindahkan panas dari dalam tubuh ikan. Pendinginan ini dapat memperlambat proses-proses biokimia yang berlangsung dalam tubuh ikan (Juniato, 2003).

Nelayan Desa Sumberbening, pantai Kondang Merak Kabupaten Malang merupakan nelayan-nelayan skala kecil yang menggunakan perahu kecil (jukung) untuk menangkap ikan. Alat tangkap jukung adalah alat tangkap sederhana yang terdiri dari tali pancing, 
pancing, penggulung, swievel dan umpan (Sudrajat et al., 2014).

Penanganan ikan-ikan hasil tangkapan nelayan Desa Sumberbening masih sangat terbatas. Karena rata-rata nelayan menggunakan kapal kecil dan pelayaran yang tidak terlalu lama (hanya satu hari waktu penangkapan atau one day trip), nelayan Desa Sumberbening hanya menyediakan media pendingin untuk mengawetkan ikan dalam bentuk kotak (styrofoam) yang berisi es batu dan diletakkan di dek kapal. Hal ini mengakibatkan es yang dibawa cenderung tidak bisa bertahan lama dalam proses mendinginkan ikan hasil tangkapan.

Kegiatan IbM ini akan menekankan pada pentingnya proses pengawetan ikan hasil tangkapan untuk menjaga kesegarannya. Dalam kegiatan ini, nelayan diberikan sebuah alat yang disebut dengan alat portable insulated fish storage box. Alat ini merupakan media penyimpanan dan pengawetan ikan yang berupa kotak atau box yang dilengkapi dengan sistem insulator sehingga es yang ada di dalam kotak tidak mudah mencair. Alat ini sangat efektif untuk memperlambat laju mencairnya es sehingga proses pengawetan dapat lebih optimal. Selain itu, alat ini memiliki keuntungan diantaranya memperpanjang umur simpan ikan, memperbaiki kualitas ikan, meningkatkan higienitas dan keamanan ikan untuk dikonsumsi yang pada akhir akan meningkatkan nilai jual ikan. Karena sifatnya yang portable, alat ini memudahkan proses penanganan ikan untuk didistribusikan ke tempat yang lebih jauh.

\section{TARGET DAN LUARAN}

Target kegiatan IbM ini adalah kedua mitra yaitu Kelompok Nelayan Bina Mina Rukun dan Kelompok Nelayan Kondang Merak dapat mempertahankan kondisi kesegaran ikan lebih dari 3 hari. Kegiatan ini akan menjadi salah satu solusi untuk meningkatkan daya jual ikan hasil tangkapan sehingga dapat dijual dalam skala yang lebih besar lagi, tidak hanya di tempat pelelangan ikan Desa Sumberbening namun juga pada TPI yang lebih besar seperti TPI Sendang Biru.

Kegiatan iptek bagi masyarakat (IbM) ini akan menghasilkan luaran sebagai berikut:

1. 6 unit portable insulated fish storage box yang dapat menampung sebanyak $200 \mathrm{~kg}$ ikan hasil tangkapan untuk nelayan di Desa Sumberbening Kabupaten Malang

2. Publikasi teknologi tepat guna tentang disain portable insulated fish storage box yang sesuai untuk nelayan di Desa Sumberbening Kabupaten Malang

\section{METODE PENELITIAN}

Program IbM Portable Insulated Fish Storage Box dilaksanakan di Desa Nelayan Sumberbening, Kecamatan Bantur, Kabupaten Malang. Desa Sumberbening merupakan desa yang terletak di sepanjang Pantai Kondang Merak dengan posisi geografis $112^{\circ} 30^{\prime} 00^{\prime \prime}$ BT - 112 $34^{\prime} 00,00^{\prime \prime}$ BT dan antara $8^{\circ} 18^{\prime} 00^{\prime \prime}$ LS - 8 $8^{\circ} 25^{\prime} 00^{\prime \prime}$ LS. Program ini rencananya akan dilaksanakan selama tujuh bulan yaitu dari bulan April-November 2017. Tahapan kegiatan dapat dilihat pada Gambar 1.

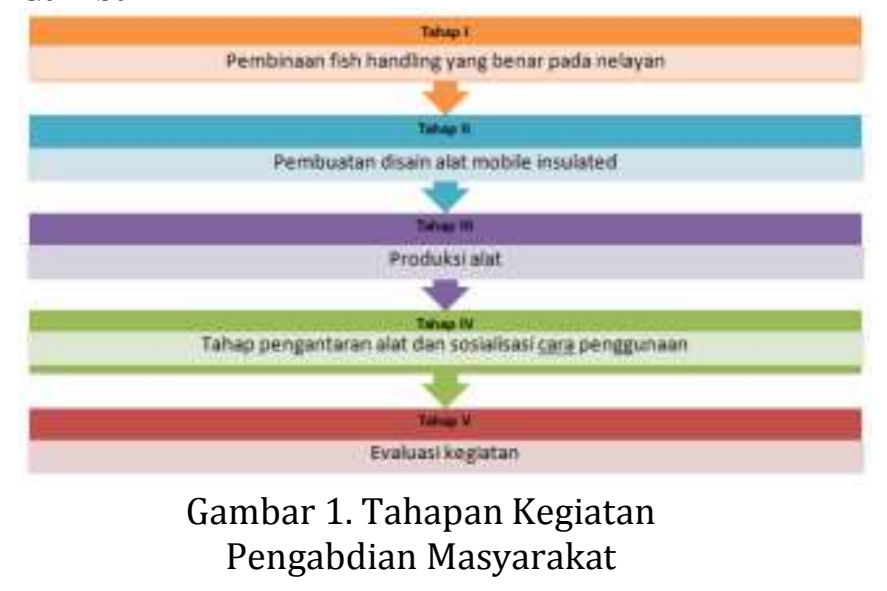

\subsection{Pembinaan fish handling yang benar pada nelayan}

Pada tahap ini merupakan tahap pertama kegiatan yang merupakan serangkaian kegiatan sosialisas dan pembinaan dalam bentuk mengadakan 
penyuluhan dan pelatihan tahap pertama penyuluhan, pelatihan dan demonstrasi tentang cara bagaimana menjaga mutu kesegaran ikan melalui berbagai teknik pengawetan. Pada pelatihan ini juga akan diberikan informasi tentang teknik handling dan packing ikan segar yang benar. Melalui penguasaan materi ini diharapkan nelayan mampu menjaga kualitas ikan hasil tangkapannya secara mandiri. Kegiatan ini rencana nya akan diikuti oleh anggota kelompok nelayan mitra di Desa Sumberbening.

\subsection{Desain Alat Portable Insulated Fish Storage Box}

Desain alat ini disajikan pada Lampiran 2 dengan dimensi 106x62x75 $\mathrm{cm}$. Alat Portable Insulated Fish Storage Box akan dibuat dengan karakteristik sebagai berikut:

- Wadah berinsulasi terdiri dari 2 lapisan yaitu lapisan luar dan dalam. Antara lapisan luar dan dalam diberi isolator. Lapisan ini terbuat dari plastik atau fiberglass. Wadah ini terdiri 2 pasang agar dapat diletakkan pada sepeda motor dengan kapasitas 100-300 liter

- Penyangga logam cor: logam cor ini dibuat semacam kerangka sedemikian rupa agar wadah insulator dapat diletakkan dengan tepat tanpa menimbulkan goncangan selama perjalanan.

- Isolator yang digunakan adalah polyurethane A dan B yang dicorkan pada kedua sisi dinding cold box stainless steel untuk menahan penetrasi panas dari luar sehingga es yang ditambahkan tidak mudah mencair.

\subsection{Produksi Alat}

Alat Portable Insulated Fish Storage Box rencananya akan dibuat sebanyak 6 unit. Proses produksi alat tersebut dilakukan selama 14 hari.

\subsection{Tahap Pemasangan Alat dan Sosialisasi}

Alat Portable Insulated Fish Storage Box diletakkan di atas lambung kapal pada tempat yang mudah dijangkau. Alat ini harus diletakkan pada tempat yang tidak terkena cahaya matahari langsung. Alat diletakkan pada kapal ukuran relatif kecil. Pada tahap ini juga dilakukan serangkaian kegiatan serah terima dan sosialisasi penggunaan alat.

\subsection{Evaluasi Kegiatan}

Penerapan alat dilapangan dilakukan berturut-turut selama satu bulan dan upaya khusus untuk memantau setelah program ini selesai adalah dengan melihat efektifitas alat ini dengan parameter dimanfaatkan nelayan Desa Sumberbening untuk menggunakannya dengan cara mengadakan penyuluhan-penyuluhan dan mengarahkan dalam konsultasi cara pembuatan serta menerapkan alat ini. Evaluasi akan dilaksanakan pada bulan ke 4.

\section{HASIL DAN LUARAN YANGB DICAPAI}

\subsection{Desain Desain alat Portable Insulated Fish Storage Box}

Desain alat Portable Insulated Fish Storage Box. Pada tahap ini dilakukan penyempurnaan desain alat Portable Insulated Fish Storage Box dengan spesifikasi sebagai berikut :
a.Dimensi $\quad: 106 \times 62 \times 75 \mathrm{~cm}$
b.Volume $\quad:>100 \mathrm{~kg}$
c.Bahan : bahan Polyethylene dan Polyurethene A dan B
d.Berat $: 23 \mathrm{~kg}$
e. Ketebalan : $5 \mathrm{~mm}$

Berdasarkan hasil diskusi, adapun sketsa desain alat Portable Insulated Fish Storage Box disajikan pada Gambar 2.

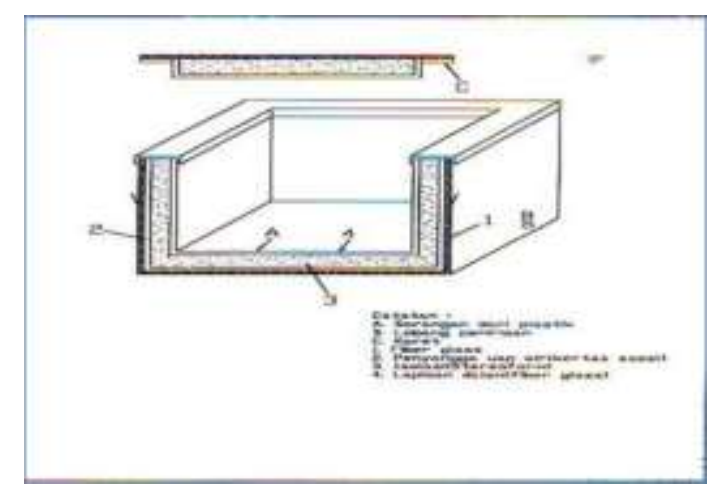




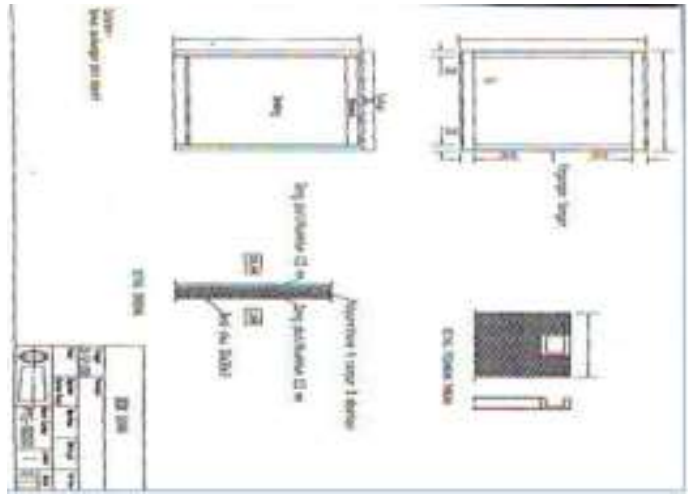

Gambar 2. Desain alat Portable Insulated Fish Storage Box

Konstruksi peti berinsulasi terdiri dari 3 bagian pokok struktur konstruksinya :

1. Rangka wadah yang terdiri tulang rangka dari kayu dengan dinding peti dari fiberglass sebagai penunjang kekuatan dasar sebuah peti.

2. Lapisan insulator yang terbuat dari dari poliuretan (insilator yang paling baik) atau poliurethan yang tidak menyerap uap air yang berfungsi menahan perpindahan panas.

3. Lapisan penutup di dinding peti yang terbuat dari plat fibreglass tebal 5-6 $\mathrm{cm}$ yang bersifat kedap air. Lapisan kedap air ini terutama digunakan untuk pelapis peti bagian dalam.

\subsection{Proses Pembuatan Alat}

Proses pembuatan alat dilakukan setelah mendapat persetujuan dari mitra. Proses pembuatan dilakukan setelah mengumpulkan bahan yang akan digunakan dalam membuat alat Portable Insulated Fish Storage Box (Gambar 3) sebagai berikut :

1. Resin Yukalac 157 BQTN-Ex

2. Besi hollow $4 \mathrm{~mm}$

3. Catalyst Mepoxe

4. Styrene Monomer

5. Pigment

6. Triplex

7. Paku

8. Aluminium plat

9. Fiberglss

10. Poliuretan rigid foam

Bahan yang diperlukan dibeli dan dikumpulkan secara bertahap selama lima bulan (Maret-Juli 2017). Hal ini dikarenakan pembuatan alat juga dilakukan secara bertahap sehingga pada Bulan Juli ke enam alat Portable Insulated Fish Storage Box telah selesai dibuat. Adapun tahapan proses pembuatan alat (Gambar 4) adalah,

1. Pengukuran dan pemotongan rangka besi

2. Pengelasan rangka

3. Pemasangan tripleks

4. Pemasangan isolator (poliuretan rigid form)

5. Pemasangan plat aluminium

6. Pemasangan fiberglass

7. Perekatan (resin, katalis dan pigmen biru)

8. Penghalusan

9. Finishing dan selesai

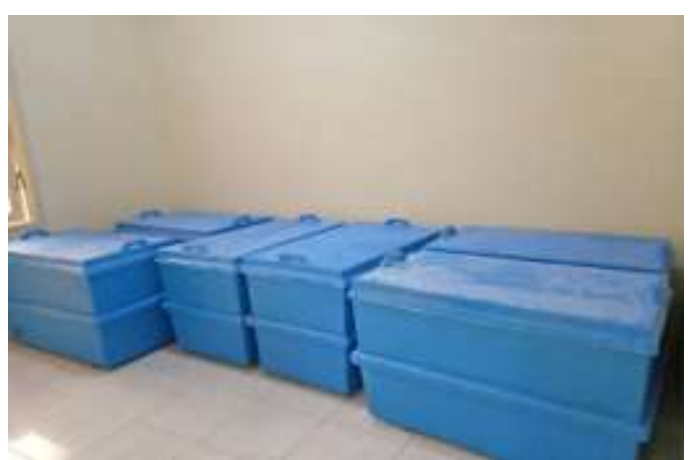

Gambar 3. Portable Insulated Fish Storage Box
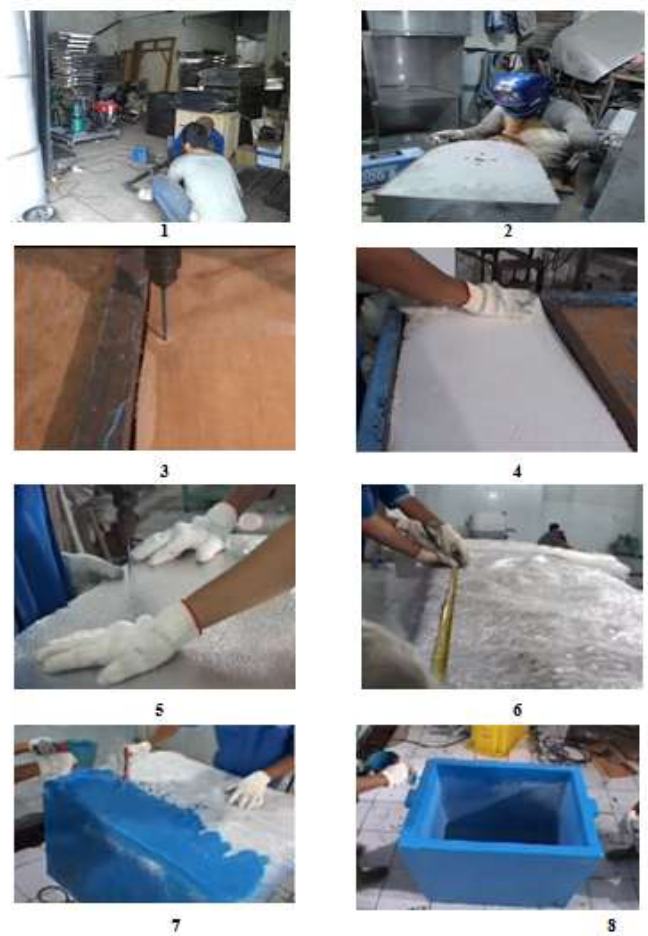

Gambar 4. Proses Pembuatan Alat 


\subsection{Pelatihan}

Serangkaian kegiatan sosialisas dan pembinaan (Gambar 5) dalam bentuk mengadakan penyuluhan dan pelatihan tahap pertama penyuluhan, pelatihan dan demonstrasi tentang cara bagaimana menjaga mutu kesegaran ikan melalui berbagai teknik pengawetan. Pada pelatihan ini juga akan diberikan informasi tentang teknik handling ikan segar yang benar. Materi mengacu pada Buku Penanganan Ikan Hasil Tangkapan di atas Kapal yang dikeluarkan oleh Balai Besar Pengembangan Penangkapan Ikan Semarang (2012). Melalui penguasaan materi ini diharapkan nelayan mampu menjaga kualitas ikan hasil tangkapannya secara mandiri. Kegiatan ini rencana nya akan diikuti oleh anggota kelompok nelayan mitra di Desa Sumberbening. Materi yang akan disampaikan sebagai berikut :

1. Parameter kualitas ikan hasil tangkapan

2. Penentuan Kesegaran ikan

a. Metode penentuan secara fisik

b. Uji kimia

c. Metode penentuan secara mikrobiologi

d. Metode penentuan ikan secara sensorik

3. Proses kemunduran mutu

4. Metode handling ikan di kapal dengan cool box

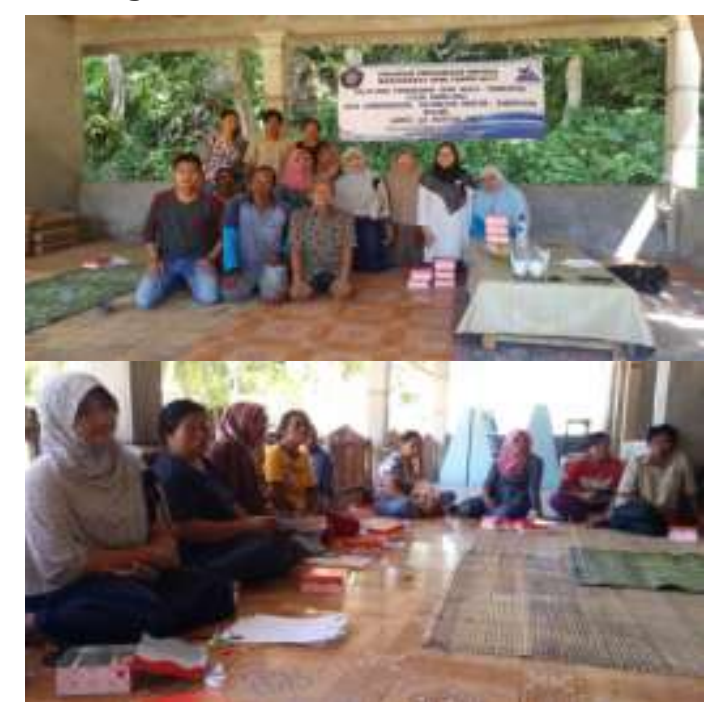

Gambar 5. Penyuluhan Fish Handling bagi Mitra

\section{KESIMPULAN}

Pada kegiatan ini telah dibuat 6 unit alat Portable Insulated Fish Storage Box dengan 106x62x75 cm dengan kapasitas tampung ikan $>100 \mathrm{~kg}$. Kegiatan ini juga akan melaksanakan penyuluhan dan pelatihan bagaimana menjaga mutu kesegaran ikan melalui berbagai teknik pengawetan untuk kedua mitra di Desa Sumberbening, Kecamatan Bantur, Kabupaten Malang. Melalui kegiatan ini diharapkan mampu membuat mutu ikan yang dijual akan baik dan pada akhirnya akan membantu menaikkan kesejahteraan nelayan Desa Sumberbening.

\section{DAFTAR PUSTAKA}

Junianto, 2003. Teknik Penanganan Ikan. Penebar Swadaya. Jakarta. Sudrajat, S.M.N.I., Rosyid, A., Bambang, A.N., 2004. Analisis Teknis dan Finasial Usaha Penangkapan Ikan Layur (Trichiurus sp) dengan Alat Tangkap Pancing Ulur (Handline) di Pelabuhan Perikanan Nusantara Pelabuhan Sukabumi. J. Fish. Resourc. Util. Manag. Technol. 3, 141-149. 